\title{
Parenting styles and peer-pressure as predictors of substance abuse among university students
}

\author{
Gboyega E. Abikoye ${ }^{1, *}$, Adeniyi M. Sholarin², James A. Adekoya ${ }^{3}$ \\ ${ }^{1}$ Department of Clinical Psychology, Niger Delta University, Wilberforce Island, Bayelsa State, Nigeria \\ ${ }^{2}$ Department of Psychology, Covenant University, Ota, Ogun State, Nigeria \\ ${ }^{3}$ Department of Psychology \& Sociology, Olabisi Onabanjo University, Ago-Iwoye, Ogun State, Nigeria
}

\section{Email address:}

ageabikoye@yahoo.com (G. E. Abikoye)

\section{To cite this article:}

Gboyega E. Abikoye, Adeniyi M. Sholarin, James A. Adekoya. Parenting Styles and Peer-Pressure as Predictors of Substance Abuse among University Students. Psychology and Behavioral Sciences. Vol. 3, No. 2, 2014, pp. 55-59. doi: 10.11648/j.pbs.20140302.14

\begin{abstract}
The study investigated the prevalence of substance abuse and its prediction by parenting styles and peer pressure among university students. Participants in this cross-sectional survey consisted of four hundred and fifty two randomly selected undergraduates of Olabisi Onabanjo University (OOU), Ago-Iwoye. The sample consisted of 221 (48.9\%) males and 231 (51.1) females. Participants' age ranges were as follow: 126 (27.9\%) were aged between 18 and than 20 years, $312(69.0 \%)$ were aged between 20 and 25 years while 14 (3.1\%) were aged between 25 and above. Students who were younger than 18 years were excluded from participating in the study. Results indicated that about $47 \%$ of all respondents reported current use while 58\% reported lifetime use of one or more psychoactive substances. Prevalence rates of use of all categories of drugs by respondents are presented in Table 1. Life time prevalence rate was highest for alcohol $(43.14 \%)$, followed by tobacco $(37.61 \%)$, stimulants $(22.57 \%)$, cannabis $(18.14 \%)$, sedatives $(17.92 \%)$ and heroin $(12.17 \%)$. parenting styles (permissive parenting, authoritarian parenting and authoritative parenting), peer pressure and sex jointly predicted substance abuse among students $(\mathrm{R}=.48 ; \mathrm{F}=9.16 ; \mathrm{p}<.01)$ by accounting for $23 \%$ of the variances in substance abuse. The study highlighted the important roles of parenting styles (especially authoritative parenting), peer pressure, age and gender in understanding students' substance abuse problem. The study concluded that these variables should be factored into intervention programmes aimed at stemming the tides of substance abuse among university students. It is also important for relevant interventions to commence before students enter the university since many young people come to the university or college with pre-existing perceptions and expectations concerning substance use, and often start university with already established habits and orientations.
\end{abstract}

Keywords: Substance Abuse, Parenting, Peer Pressure, Students, Nigeria

\section{Introduction}

Substance abuse is one of the most pervasive social problems in the world. It is a behaviour that most societies views as being detrimental to physical, social, psychological and spiritual health due to its many deleterious effects. Substance abuse has been defined as an excessive use of addictive substances, especially when such consumption or misuse of a substance is not for therapeutic purposes but rather for the purpose of altering the normal functioning of the mind and body (1). Substance abuse among various populations and in virtually every country of the world is assuming an increasingly alarming dimension, a tendency which if, left unchecked, could spell disasters of an unimaginable proportion (2).
At the individual level, substance abuse has been implicated in many forms human morbidity and mortality, and is a leading cause of preventable deaths in many countries of the world $(3,4)$. Substance abuse is a major cause of physical conditions such as liver, cardiovascular, and cranial problems. Other problems include some degree of tolerance and withdrawal syndrome, characterized by nervousness, irritability, drowsiness, energy loss, difficulty concentrating, impaired physical performance, headaches, fatigues, irregular bowels, insomnia, dizziness, cramps, palpitation, tremors, seating and cravings (5 - 7). Additionally, substance abuse has been implicated in majority of the cases of vehicular fatalities worldwide, with attendant effects of physical deformity, loss of property, loss of jobs, loss of esteem and even loss of lives. In 
addition, substance misuse is known have a causal relationship with many psychological disorders including mental and behavioural disorders. Substance abuse is a leading cause of violence among individuals is a major cause of premature deaths $(3,8,9)$.

Apart from the various effects of substance abuse for the general population, its negative impacts for the youths (especially students) are far-reaching. Students who abuse drugs persistently face an array of possible consequences raging from lowered commitment to education, declining grades, increased potential for dropout and high truancy rate $(3-5,8)$. Suicides, homicides, and accidental injuries have all been linked to substance abuse among students (3, 8). Other researchers have found a high prevalence of depression, development lag, apathy and withdrawal among substance-abusing students (10), coupled with the fact that siblings and parents are affected profoundly by undergraduate involvement in substance abuse as this may drain family financial and emotional resources (10).

One factor that researchers have figured as playing a key role in students substance abuse but which has not received adequate research attention in Nigeria is parenting styles. Parenting style is a complex activity that includes much specific behaviour that works individually and together to influence child's life form. Parenting style captures two important elements of parenting: parental responsiveness and parental demandingness (11). Parenting responsiveness (also referred to as parental warmth or supportiveness) refers to the extent to which parents intentionally foster individuality, self-regulation, and self-assertion by being attuned, supportive, and acquiescent to children's special needs and demands (12). Parental demandingness (also referred to as behavioural control) refers to the claims parents make on children to become integrated into the family as a whole, by their maturity demands, supervision, disciplinary efforts and willingness to confront the child who disobeys (12). However when parental responsiveness and parental demandingness is crossed, it yields three parenting styles. These parenting styles are: authoritative parenting style, which is responsive and demanding; authoritarian parenting style, which is demanding but not responsive; and permissive or indulgent parenting style, which is responsive but not demanding (12).

In buttressing the importance of parenting styles on children's behavioural outcomes, (12) correlated parenting styles with school achievement and with adolescent psychological maturity which involves drug involvement largely which they defined as their sense of self-reliance and identify. They found that adolescents from authoritative homes reported significantly higher levels of more positive outcomes such as self conceptualizations, greater well being, and fever behavioral problems, including drug involvement and failure to thrive.

Many researchers have also consistently placed the explanation of many forms of negative behaviour among youths in the social domain, especially on the influence of peer groups. For instance, (13) found that the main reasons that majority of their sample of college students cited for substance abuse, especially excessive drinking, was peer pressure (13). The influence of the peer group becomes particularly pervasive for the youth from a weak family setting, such as from permissive parents. The university system, which epitomizes independence and freedom (hitherto mismanaged, restricted, or unavailable for many youths) therefore provides a veritable environment for peer influence to wax strong on individuals. In such a situation, peer influence could play a big role in students' substance abuse.

Several studies have reported alarming rates of substance abuse in student populations (14-22). The university experience is unique as it provides students with the first opportunity to be part of a larger group of peers without parental supervision. It also represents the perceived (by students) last period of freedom before taking on the responsibilities of adulthood. This makes them more vulnerable to try novel, previously prohibited and sometimes illicit experiences $(23,24)$. Furthermore, it has been suspected that the use of substances like cannabis, heroin, cocaine and to some extent alcohol may have to do with the spreading of secret cults among university students $(25,26)$.

Given the serious effects that substance use portends for the students, their families and the society at large, and the limited empirical research in this area in Nigeria, it is important to empirically examine the extent of the problem substance abuse among students with a view to throwing more light on the issue, and making relevant recommendations to stakeholders, towards ameliorating the situation. The purpose of the present study, therefore, was to empirically examine substance abuse among undergraduate students of a non-residential Nigerian university. Also, the study was aimed at examining the influence of parenting styles and peer pressure as well as some demographic variables on substance use. We hypothesized that authoritative parenting style and less peer pressure would be associated with less substance abuse. We also hypothesized that males would be report more substance abuse than female students. Finally, we tested the hypothesis that age would have a significant influence on substance abuse.

\section{Method}

\subsection{Design/Participants}

The study was a cross-sectional survey, utilizing the ex post facto design in which variables were not actively manipulated by the researchers. Participants consisted of four hundred and fifty two randomly selected undergraduates of Olabisi Onabanjo University (OOU), Ago-Iwoye. The sample consisted of 221 (48.9\%) males and 231 (51.1) females. Participants' age ranges were as follow: $126(27.9 \%)$ were aged between 18 and than 20 years, $312(69.0 \%)$ were aged between 20 and 25 years 
while $14(3.1 \%)$ were aged between 25 and above. Students who were younger than 18 years were excluded from participating in the study.

\subsection{Measures}

Data was collected with the use of a structured and validated questionnaire. Background variables were, such as age, sex, and level of study, were assessed in the first part of the questionnaire. Parenting styles were assessed with the Parenting Care Scale (12). The scale was designed to identify the dominant child rearing style that is exhibited by children's parents or care takers. Scores that are higher than the norms indicate the dominance of the particular parenting style (authoritative, authoritarian or permissive) by respondents' parents. The scale has been widely used and is reputed for its robust psychometric properties (27). In the present study, an alpha coefficient of 0.69 was obtained for the scale in this study.

Substance use was assessed in this study with modified Montgomery Substance Abuse Questionnaire (28). The questionnaire has two parts. In the first part, a list of substances are provided (including alcohol, nicotine, anabolic steroids, inhalants, sedatives, stimulants, dissociative anaesthetics, opioids, etc.) and respondents were asked to indicate any of the substances that they had ever used, had used in the last 30 days or were using currently. The second part consists of 12 items assessing respondents' substance abuse in the last 12 months, by ticking either "Yes" or "No" for each item (scored 1 and 0 respectively). Respondents' composite scores are used to determine the presence and degrees of substance use /abuse. A Cronbach alpha of 0.83 was obtained for the instrument in the present study.

\subsection{Procedure}

A multi-stage sampling technique was used to select departments, courses and students who took part in the study. Random (balloting) sampling technique was used to select participants from the five departments from the Main Campus of OOU. Twenty-five students offering compulsory courses were randomly selected from the four levels of each department (using systematic sampling technique), totaling 100 students per department. Questionnaires were administered during lectures, with the prior consent of lecturers in charge of the courses. Informed consent was obtained by participants' signing of the "Informed Consent" form attached to the questionnaire. Of the 500 questionnaire administered, 452 were returned with usable data, representing a $90.4 \%$ return rate.

\section{Results}

Overall, about $47 \%$ of all respondents reported current use while $58 \%$ reported lifetime use of one or more psychoactive substances. Prevalence rates of use of all categories of drugs by respondents are presented in Table 1.
Life time prevalence rate was highest for alcohol (43.14\%), followed by tobacco $(37.61 \%)$, stimulants $(22.57 \%)$, cannabis $(18.14 \%)$, sedatives $(17.92 \%)$ and heroin $(12.17 \%)$. The least were inhalants and anabolic steroids with $0.66 \%$ and $0.44 \%$ respectively. The previous 30 days and current use prevalence rates followed similar patterns but with lower rates than the life time use.

Table 1. Prevalence rates of substance use among respondents $(N=452)$.

\begin{tabular}{lcccccc}
\hline \multirow{2}{*}{ Drug } & \multicolumn{2}{c}{ Lifetime Use } & \multicolumn{2}{c}{ Previous 30 } \\
days use & \multicolumn{2}{c}{ Current use } \\
\hline & $\mathbf{n}$ & $\mathbf{\%}$ & $\mathbf{n}$ & $\mathbf{\%}$ & $\mathbf{n}$ & $\mathbf{\%}$ \\
\hline Alcohol & 195 & 43.14 & 163 & 36.06 & 129 & 28.54 \\
Tobacco & 170 & 37.61 & 128 & 28.32 & 115 & 25.44 \\
Stimulant & 102 & 22.57 & 74 & 16.37 & 64 & 14.16 \\
Cannabis & 82 & 18.14 & 71 & 15.71 & 68 & 15.04 \\
Sedatives & 81 & 17.92 & 42 & 9.92 & 38 & 8.41 \\
Heroin & 55 & 12.17 & 23 & 5.09 & 23 & 5.09 \\
Cocaine & 43 & 9.51 & 20 & 4.42 & 18 & 3.98 \\
Opium & 27 & 6.00 & 18 & 3.98 & 12 & 2.65 \\
Hallucinogens & 08 & 1.77 & - & - & - & - \\
Inhalants & 03 & 0.66 & - & - & - & - \\
Anabolic & 02 & 0.44 & & & & \\
Steroids & 02 & & & & & \\
\hline
\end{tabular}

We tested the hypothesis that parenting styles (permissive parenting, authoritarian parenting and authoritative parenting), peer pressure and sex would be significantly associated with substance use, using a multiple regression analysis (see Table 2). Results indicated that parenting styles (permissive parenting, authoritarian parenting and authoritative parenting), peer pressure and sex jointly predicted substance abuse among students ( $R$ $=.48 ; \mathrm{F}=9.16 ; \mathrm{p}<.01)$ by accounting for $23 \%$ of the variances in substance abuse. In terms of independent prediction, all the predictor variables were significantly associated with substance abuse. Specifically, more permissive parenting was significantly associated with more substance abuse $(\beta=.28 ; \mathrm{t}=5.86 ; \mathrm{p}<.05)$.

Table 2. A summary table of multiple regression showing the independent and joint prediction of adolescent drug use by parenting styles and peer pressure.

\begin{tabular}{llllll}
\hline VARIABLES & $\boldsymbol{\beta}$ & $\mathbf{t}$ & $\mathbf{F}$ & $\mathbf{R}$ & $\mathbf{R}^{2}$ \\
\hline Permissive parenting & $.28^{*}$ & $5.86^{*}$ & & & \\
Authoritarian & $.27^{*}$ & $5.21^{*}$ & & & \\
parenting & & & 9.16 & $.48^{* *}$ & .23 \\
Authoritative & $-.19 *$ & $-4.37^{*}$ & & & \\
parenting & $.22^{*}$ & $4.95^{*}$ & & & \\
Peer pressure & $-.33^{* *}$ & $-8.53^{*}$ & & & \\
Sex & & & \\
\hline
\end{tabular}

Authoritarian parenting was also significantly associated with more substance abuse $(\beta=.27 ; \mathrm{t}=5.21 ; \mathrm{p}<.05)$. Similarly, more peer pressure was significantly associated with more substance abuse $(\beta=.22 ; \mathrm{t}=4.95 ; \mathrm{p}<.05)$. However, authoritative parenting was associated with less substance abuse $(\beta=.-19 ; \mathrm{t}=-4.37 ; \mathrm{p}<.05)$. Finally, being a male was significantly associated with more substance abuse $(\beta=.-33 ; \mathrm{t}=-8.53 ; \mathrm{p}<.05)$. The influence of age on substance abuse was examined using a one-way ANOVA 
(Table 3). Age was divided into three levels: Less than 20, 20-24, and 25 and above, results indicated that there was a significant influence of age on substance abuse $\{\mathrm{F}(2,449)$ $=15.04 ; \mathrm{p}<.01\}$, with the students aged less than 20 years reporting the highest level of substance abuse $(\mathrm{M}=28.71 \pm$ 8.73) relative to those aged 20 to $24(\mathrm{M}=27.22 \pm 8.88)$ and those aged 25 years and above $(M=22.93 \pm 7.61)$.

Table 3. Analysis of variance of the influence of age on substance abuse.

\begin{tabular}{llllll}
\hline Sources & SS & df & MS & F & P \\
\hline Between Groups & 1932.03 & 2 & 966.02 & 15.04 & $<.01$ \\
Within Groups & 28840.22 & 449 & 64.23 & & \\
Total & 30772.25 & 451 & & & \\
\hline
\end{tabular}

\section{Discussion}

We investigated the psychoactive substances commonly abused by students in the present study. Findings indicated high prevalence of substance use among the respondents. About $58 \%$ of the respondents reported having used at least one of the psychoactive substances in their lifetime while almost a half of the respondents were current users. These rates are similar to prevalence rates among students as reported by other researchers (15-22). As opined by Makanjuola et al (2007), a possible explanation for the high prevalence of substance use among students could be the fact that the university experience is unique as it provides students with the first opportunity to be part of a larger group of peers without parental supervision. This makes students more vulnerable to try novel, previously prohibited and sometimes illicit experiences. Also, alcohol, tobacco, stimulants, cannabis and sedatives were found to be the most commonly abused substances, which also corroborate several empirical reports (15-19).

On the prediction of parenting styles, we found parenting styles to be significantly associated with substance abuse, with authoritative parenting style being the beneficial style. This corroborates previous evidence (12) that adolescents from authoritative homes reported significantly higher levels of more positive outcomes such as self conceptualizations, greater well being, and fever behavioral problems, including drug involvement and failure to thrive.

Gender was found to be significantly associated with substance abuse, with males students more vulnerable. This finding of the present study lend support to earlier positions researchers $(3,5,8,10,14,27)$, who reported that male students were, by far, more likely than their female counterparts to abuse substances and justify such behaviour as a means of coping with the stresses and challenges of school work. Additionally, cultural factors may also explain why males abuse substances more than females. In the predominantly masculine African culture, substance use/abuse is more permissible for males whereas female substance users/abusers are viewed in a negative perspective. Substance use in many parts of Africa (Nigeria inclusive) is viewed as a masculine trait and is even tacitly encouraged among male children by some parents. Such culturally backed behaviours may find more ready and unbridled expression when a boy finds himself in a university, where he now enjoys more liberty.

Relatively younger students reported more substance abuse than their older counterparts. As noted by (14), younger students may not be as capable of exerting control over their substance use behaviours as their colleagues who are "more mature". Moreover, it is quite possible that the excitement of leaving home/parents for a "freer environment" might be too much for the younger students to control. Many young students feel caged by their parents (especially children of overprotective parents) and they yearn for opportunities to be "freed". When freedom eventually comes by way of admission into the university, knowing how to enjoy such freedom in a healthy, safe and purposeful manner is, more often than not, a big problem.

\section{Conclusions}

In conclusion, prevalence of substance abuse is quite high among our sample, and by extension undergraduate students. The study also highlighted the important roles of parenting styles (especially authoritative parenting), peer pressure, age and gender in understanding students' substance abuse problem, we are of the considered view that these variables should be factored into intervention programmes. It is also important for relevant interventions to commence before students enter the university since many young people come to the university or college with pre-existing perceptions and expectations concerning substance use, and often start university with already established habits and orientations. Limiting intervention to merely reeling out rules and regulations in the university without taking the salient background issues into consideration may, therefore, not yield the desired results.

Caution should be adopted in interpreting and generalizing the findings of this study, especially considering the following limitations of the study. First, the fact that only $23 \%$ of the variance in substance use was explained by the variables in the present study indicated that there are other explanations for students' substance use. Second, the study was a survey conducted in only one Nigerian university. The sample may, therefore, not necessarily typify the overall student community in the university or other Nigerian universities. The above-mentioned limitations, however, did not negate the valuable contributions of the study to the body of knowledge on this vital issue.

\section{References}

[1] Hewitt BG \& Enoch G. Alcoholism. Microsoft Encarta. Redmond, WA: Microsoft Corporation. 2009.

[2] World Health Organization. Global Strategy to reduce the harmful use of alcohol. Geneva: Author. 2010. 
[3] Agrawal RK, Puliyel JM, Chansoria M, Mukerejee M, Kaul KK. Comparative Study of the Personality Correlates and the Nature of Drug Abuse in Schools and Colleges. Indian Journal of Pediatrics, 2007; 49 (5): 76-85.

[4] Yoon J, Higgins S, Heil S. Delay Discounting Predicts Postpartum Relapse to Cigarette Smoking among Pregnant Women. Experimental \& Clinical Pharmacology, 2007; 15(2), 176-186.

[5] Hawkins JD, Catalano RF, Miller JY. Risk and Protective Factors for Alcohol and Other Drug Problems in Adolescence and Early Adulthood: Implications for Substance Abuse Prevention. Psychology Bulletin, 1992; 12;64-105.

[6] Santi S, Best J, Brown K.S. Social Environment and Smoking Initiation. International Journal of Addiction, 1990; 25:881-903.

[7] Seeman M, SeemanTE. Health Behavior and Personal Autonomy. A Longitudinal Study of the Sense of Control in Illness. Journal of Health and Social Behavior, 1983; 24, 144-160.

[8] Ogden J. Health Psychology: A Textbook (2nd Edition). Buckingham: Open University Press. 2003.

[9] Patton QN. Adolescent Development and Behaviour Health. A Handbook of Health Enhancement. New York. 1998.

[10] Shamsuddin M, Abdul-Han NH. Smoking Behaviour on Family and Consequence in Adolescence. Psychology Journal of Social Behaviour, 2000; 20; 135-45.

[11] Maccoby EE, Martin JA. Socialization in the context of the family: Parent child interaction. In P. H. Mussen \& E. M. Hetherington (Eds.), Handbook of Child psychology:Vol. 4. Socialization, personality, and social development (4th ed.,pp. 1-101).1983.

[12] Baumrind D. The influence of parenting styles on adolescent Competence and substance use. Journal of Early Adolescence, 1991; 11, 56-95.

[13] Thakore S, Ismail Z, Jarvis S, Payne E, Keetbaas S, Payne R, Rothenburg L. The perceptions and Habits of Alcohol Consumption and Smoking among Canadian Medical Students. Academic Psychiatry, 2009; 33 (3), 197 - 197.

[14] Abikoye GE Adekoya JA. Predicting Substance Abuse in a Sample of Nigerian Undergraduates: The Role of Core SelfEvaluations and Delay of Gratification. Psychological Studies. 2010; 55 (4), 299 - 307.
[15] Makanjuola AB, Daramola TO, Obembe AO. Psychoactive Substance Use among Medical Students in a Nigerian University. World Psychiatry 2007;6:112- 114.

[16] Makanjuola AB, Daramola TO, Obembe AO. Psychoactive Substance Use among Medical Students in a Nigerian University. World Psychiatry 2007;6:112- 114.

[17] Adelekan ML. West Africa sub-region: an overview of substance abuse problems. Drugs: Education, Prevention and Policy 1996; 3:231-7.

[18] Anumonye A. Drug use among young people in Lagos, Nigeria. Bulletin on Narcotics 1980;32:39-92.

[19] Baptista T, Novoa D, Hernandez R. Substance use among Venezuelan medical And pharmacy students. Drug Alcohol Dependence 1994;34:1217.

[20] Anochie IC, Nkanginieme K. Social correlatives of drug use among secondary school students in Port Harcourt, southern Nigeria. Sahel Medical J 2000;3:87- 92.

[21] Bell R. Correlates of college student marijuana use: results of a US National survey. Addiction 1997;92:571-81.

[22] Adelekan ML, Ndom RJE, Makanjuola AB et al. Trend analysis of substance use among undergraduates of university of Ilorin, Nigeria, 1988-1998. African J Drug Alcohol Studies 2000;1:39-52.

[23] Gledhill-Hoyt J, Lee H, Strote J et al. Increased use of marijuana and other illicit drugs at US colleges in the 1990s: results of three national surveys. Addiction 2000;95:1655-67.

[24] Walsh A. Drug use and sexual behaviour: users, experimenters and abstainers. J Soc Psychol 1992;132:691-3.

[25] Leibsohn JM. Relationship between drug and alcohol use and peer group association of college freshmen as they transit from high school. J Drug Education 1994;24:177-92.

[26] Attah-Johnson FY. Attitudes of Nigerian medical students towards use and abuse of tobacco, alcohol and drugs. Drug Alcohol Dependence 1985;15:323- 34.

[27] Aje SA, Akanbi A, Folorunsho I. Problems of cultism in Nigerian schools. Ilorin: INDEMAC, 2000.

[28] Abikoye GE, Adetifa TL. Parenting Styles, Self-Esteem, and Undergraduates' Alcohol Consumption. Ilorin Journal of Sociology, 2011; 3 (1), 137 - 150.

[29] Montegomery County Court Referral Program. Substance Abuse Questionnaire. Crawfordsville: Author. 2001. 